\title{
Del discurso capitalista al neoliberalismo: apuntes sobre la producción del sujeto
}

\section{From capitalist discourse to neoliberalism: notes on the production of the subject}

\author{
Judith Elena García Manjarrés*, Leonardo Rafael Mass Torres“*
}

\author{
Universidad Metropolitana
}

Recibido: 9 de julio de 2020-Aceptado: 16 de junio de 2021-Publicado: 1 de enero de 2022

Forma de citar este artículo en APA:

García-Manjarrés, J. E., \& Mass-Torres, L. R. (2022). Del discurso capitalista al neoliberalismo: apuntes sobre la producción del sujeto. Revista Colombiana de Ciencias Sociales, 13(1), 325-347. https://doi.org/10.21501/22161201.3668

\section{Resumen}

Las economías globalizadas de mercado conllevan consecuencias de inequidad social basadas en la privatización de sectores laborales y productivos donde los sujetos se involucran en modos singulares de concebirse y construir la realidad. Propone el psicoanálisis lacaniano que el discurso capitalista deshace el lazo social, al obrar con una lógica que consiste en gozar del consumo que supone felicidad. El neoliberalismo promueve un sistema aparentemente horizontal que incorpora las capacidades empoderadas del sujeto promoviéndolo a ser emprendedor y, por tanto, convirtiendo a cada uno en gestor de su propio bienestar, 
pero impedidos para forjar lazos solidarios. No porque el sujeto pueda consumir más, queda desprovisto de su falta constitutiva; paradójicamente, la subjetividad neoliberal reproduce incesantemente un vacío que socava el reconocimiento de las diferencias del otro.

\section{Palabras clave}

Neoliberalismo; Discurso capitalista; Sujeto; Psicoanálisis; Goce; Lazo social.

\section{Abstract}

Globalized market economies entail consequences of social inequality, based on the privatization of labor and productive sectors, where subjects engage in unique ways of conceiving and constructing reality. Lacanian psychoanalysis proposes that capitalist discourse undoes the social bond, by acting with a logic that consists in enjoying the consumption that supposes happiness. Neoliberalism promotes an apparently horizontal system that incorporates the empowered capacities of the subject by promoting him to be an entrepreneur and, therefore, turning each one into a manager of his own well-being, but prevented from forging solidarity ties. Not because the subject can consume more, he is devoid of his constitutive lack; paradoxically, neoliberal subjectivity incessantly reproduces a vacuum that undermines the recognition of each other's differences.

\section{Keywords}

Neoliberalism; Capitalist speech; Subject; Psychoanalysis; Jouissance; Social bond. 


\section{Introducción}

El mundo actual afronta grandes y profundos cambios sociales en materia de economías globalizadas de mercado, con inevitables consecuencias en términos de un incremento de la inequidad social. La sociedad, organizada a partir del capitalismo neoliberal, y previamente a él, del sistema capitalista, se basa en la economía de mercado que le apuesta a la privatización de los sectores laborales y productivos, lo que sacrifica el valor estatal del mundo empresarial. Los diferentes conglomerados poblacionales agrupados en las naciones acrecientan sus intereses competitivos abocados a una exacerbada productividad, en un mercado que emerge con fuerza globalizante y donde los sujetos se involucran en modos singulares de concebirse y construir la realidad.

El capitalismo, sistema donde nace y encuentra su soporte el neoliberalismo, al deshacer el lazo social (Soler, 2011), denota un rechazo a los límites de la satisfacción subjetiva, asunto este que con el neoliberalismo se complejiza aún más pues en él, como señala Alemán: “(...) trata una vez más de afirmar su carácter contingente y, por lo tanto, el advenimiento siempre posible de otra manera de ser con los otros distinta a como se le conoce en el capitalismo" (2012, p. 52). Refiere a un discurso que proclama, hoy en día, la producción de sujetos alienados que se autoimponen la explotación imperante en el campo de la producción laboral. Sobre esto, es menester señalar, con la globalización neoliberal, el sometimiento humano a preceptos de eficacia, rendimiento y autorrealización de una vida vinculada al mercado, afín con el consumo y el endeudamiento. Con el mundo de frente al capitalismo neoliberal, el lazo social se trastoca en valor de mercancías, se trata de "la acción del mercado autorregulado" (Polanyi, 2003, p. 93), soportada, a su vez, en un sujeto basado en el intercambio productivo.

Así, la constitución psíquica del sujeto, integrado dentro del engranaje capitalista neoliberal, no está exenta de las vicisitudes subjetivas que establece el psicoanálisis en su estudio de la cultura. En este contexto, debe tenerse presente que el sujeto no puede desligarse del padecer psíquico de su época, al tiempo que este compromete su responsabilidad subjetiva. Este sujeto se articula a una verdad discursiva que elabora su lugar en el lazo social con sus semejantes. Para reiterar, si bien, la época actual está marcada por el sistema social y económico que se impone mayoritariamente, a saber, el capitalismo neoliberal, es claro que el sujeto no puede pensarse lejos o por fuera de las lógicas que ese sistema comporta y que se traducen necesariamente en la manera como el sujeto se percibe a sí mismo, se constituye y, además, establece lazo social con los otros.

Todo sujeto no solo va conforme con su modo de gozar. Del sujeto con su satisfacción hay algo, un goce, que le es solo propio, que no entra del todo al común (Alemán, 2012), al conglomerado y que se resiste a la socialización, por lo que puede decirse que expresa la más profunda diferencia entre un sujeto y otro, es decir, lo que necesariamente refiere a la singularidad. Esto indica que, si bien lo histórico-social cumple una función importante en la producción de los 
sujetos, no es menos cierto que el sujeto está inevitablemente referido a la pulsión que se resiste a ser colonizada por el discurso de cada época (Freud, 1992a). En suma, el psicoanálisis atiende esta preocupación por aquello que insiste en su paradojal conformación de padecimiento y satisfacción del sujeto en todo tiempo y que, con el capitalismo neoliberal como sistema operante en la contemporaneidad, incide necesariamente en las formas como se producen los sujetos y como aparecen ellos frente al lazo social.

Es con las propuestas teóricas de Jacques Lacan (1901-1981) que el lenguaje remite a una dimensión estructural que, conforme a lo social, resulta transindividual, es decir, como estructura que preexiste y determina a todo sujeto (Lacan, 2008c), y que es necesariamente lo constitutivo de la experiencia psicoanalítica (Lacan, 1984). Así también, si el psicoanálisis pone empeño en entender y afirmar lo anterior, es porque el lenguaje opera como medio por el cual el sujeto busca el reconocimiento del otro; de igual modo, es a partir de allí que puede pensarse el concepto de discurso que formula Lacan (2008c). Es decir, la referencia al discurso desde el psicoanálisis alude, por un lado, al lazo social -que se funda en el lenguaje y que posibilita la existencia de un sujeto (Lacan, 2008c; Butler et al., 2017) - y, por otro lado, a que ese discurso excede las palabras -si bien se trata de un discurso montado a partir del lenguaje, no debe entenderse tal condición como que para él existir necesita de palabras que se ordenen de una manera particular-.

En lo atinente al lazo social, este se sostiene por su correlato de la imposibilidad sexual, que marca el destino relacional del sujeto con los otros. En este sentido, resulta pertinente interrogar cómo, desde la versión neoliberal del capitalismo, la felicidad se convierte en un imperativo moral en una sociedad que busca, a toda costa, suprimir el sufrimiento (Han, 2017a). El lazo social que resulta afectado consiste en un deber ser de felicidad por un recorrido que traza la experiencia de un goce desregulado. El gran Otro, que establece el encuentro del sujeto con lo social, libra al sujeto a un vacío que sentencia a un goce sin límite (Alemán, 2012). Se trata de la impotencia por otorgar un sentido a la época, en la medida que las identificaciones sociales a las que se aferra el sujeto se demuestran frágiles para regular el lado mortífero de su satisfacción.

Desde los aportes del psicoanálisis lacaniano, la constitución del sujeto pasa por el significante, que rige su división subjetiva. Es en este orden simbólico donde el goce tiene su causa en el cuerpo, indicando con ello un tipo de economía política afín a lo corporal: el goce, al ir "más allá del principio de placer" (Freud, 1992b), hace del capitalismo neoliberal una forma de lazo que produce un tipo de subjetividad que adecua expansivamente el rendimiento del trabajo como actividad compulsiva y alienante. En su afán de adecuación masificante con la productividad, el neoliberalismo - como versión actual del capitalismo- ha conminado no solo al control y adiestramiento de los cuerpos, sino también a una homogenización sin precedentes que rechaza la división del sujeto; en este rechazo el neoliberalismo puja por colmar sin tregua la falta estructural en el sujeto y, con ello, hacerlo gozar en exceso. Pero ello no es sin consecuencias en el plano de las relaciones sociales: piénsese al respecto en cómo este rechazo de la condición distintiva del 
sujeto, el borramiento de las fronteras que definen el lugar de un sujeto con respecto a otro, no son posibles por cuanto la subjetividad está atravesada por lo discursivo; como señalan Laclau y Mouffe (2015), es imposible que un sistema, en efecto, logre borrar esas diferencias.

Ahora, el capitalismo neoliberal es un sistema que retira al Estado de la operación de los bienes públicos, de la inclusión de este en los servicios primarios como agua, energía, educación y salud, entre otros, y pone a ese Estado al servicio del mercado (Alemán, 14 de marzo de 2013). Se trata de un sistema que toma para sí el orden del Estado y que, además, regula lo ateniente a su institucionalidad, dando paso a nuevas lógicas dominantes que parecen, indica Alemán (14 de marzo de 2013), haberse apropiado de novedosas formas en que opera el tejido social, a partir de la competencia y el exceso de rendimiento de los sujetos en pro de ganancia económica. De este modo, aquello que se trataba desde lo público y era perteneciente a la masa poblacional -a todos los asociados que conforman un país-, se vuelve privatizado. Así, el gasto sigue siendo de los ciudadanos de dicho país, que pagan con sus tributos, pero la ganancia pasa a manos privadas de quienes tienen el capital que sostiene el sistema económico. Tal cosa sugiere, entonces, el surgimiento de nuevas formas de gobierno y, por tanto, nuevos vínculos entre gobiernos y ciudadanos, pero también nuevos discursos con lógicas donde los sujetos se inscriben y producen lazo social, así también respecto de sus derechos. Se trata del discurso oficial de gobierno, dirigido ahora por el sistema capitalista neoliberal que rige a los asociados de la nación en la que él opere y que, necesariamente, comporta efectos sobre el lazo social que dichos sujetos establecen entre sí.

Lo anterior permite atisbar la función del capitalismo neoliberal no solo como un creciente poder económico, sino también político (Castillo et al., 2019). Sobre estas lógicas del capitalismo neoliberal son relevantes las relaciones discursivas de los sujetos con los goces subjetivos, toda vez que ahí el mercado se ha impuesto como tendencia hacia la circulación en la compra y venta de mercancías. Este modo de discurso fundamenta un sujeto capaz de animar la vinculación mercantil y el sentido de una explotación psíquica basada en el consumo ligado al mandato de goce que impone el sistema. El sujeto neoliberal dinamiza la economía de mercado al ser vaciado de reflexión, consumido por el consumo e identificado al lugar de objeto. El borramiento de la singularidad del sujeto coincide con un intento de borrar las diferencias frente a la economía que opera en lo social y afecta también al uno por uno: la brecha que separa cada vez más a ricos y pobres aparentemente se ha resuelto en tiempos actuales, en la conformación de un tipo de clase media que sujeta a la experiencia crediticia la asume como su destino social. Es un imaginario en el que algunos suponen haber resuelto el problema, pues tienen ingresos y también deudas, pero pese a tal cosa, es claro que el sistema capitalista neoliberal cada vez deja más excluidos a aquellos que no poseen capital, que son incluso mayoría (Žižek, 2016). Esto merece atención por cuanto la desregulación no solo acude a los mercados con su desenfreno productivo y consumista, asimismo, opera sobre la subjetividad y, por ende, en el lazo social que posibilita el usufructo al otro en su capacidad de fuerza de trabajo. 
Las políticas capitalistas neoliberales promueven el rompimiento del lazo social al propender con sus lógicas económicas por las diferencias e inequidades entre unos y otros sujetos. De esta manera, se acrecienta la brecha diferencial de los pequeños narcisismos en la que el mismo sujeto queda, si bien como gestor de su propio bienestar, también expuesto a la voracidad del Otro. De este modo, el capitalismo neoliberal confronta al sujeto con lo Real de la escasez y lo atrapa en lo especular de lo bello. Lo social consiste en una afección que desmiente la Ley, también la existencia del otro; no se trata del rechazo de la percepción del mundo exterior, sino de las consecuencias que la percepción provoca sobre la creencia que el sistema intenta sostener: se niegan las consecuencias tratando de defender sus políticas consumistas. Obra, así, una suerte de empoderamiento social por parte de sujetos en apariencia fuertes, todo poderosos, empero, consumidos por dentro con la sensación de impotencia, melancolía, agresión al otro.

\section{Metodologia}

El presente artículo toma como referente el paradigma interpretativo desde el cual el conocimiento es posible por medio de la interacción del investigador y su objeto de estudio, y donde el uno no puede ser desligado del otro (González-Rey, 1997). Así, ambos son determinados por la observación y el diálogo entre ellos: el investigador se ubica en el lugar de intérprete de los textos de diferentes autores que sirven para alimentar la investigación; es decir, el sujeto investigador utiliza la hermenéutica para trabajar con los textos base, encontrarles un sentido en referencia al objeto de estudio y proponer un diálogo que, a su vez, permita alcanzar los objetivos que propone la investigación.

La investigación cualitativa sirve como soporte al paradigma interpretativo que, a su vez, es afín a las propuestas realizadas por Sigmund Freud acerca del psicoanálisis como método de investigación, pues sirve para pensar incluso fenómenos referidos no solo a la clínica sino también a lo social, toda vez que en ellos se encuentra inmerso el sujeto. Asunto que lleva a Freud (1992c) a formular:

Psicoanálisis es el nombre: (...) 1) de un procedimiento que sirve para indagar procesos anímicos difícilmente accesibles por otras vías; 2) de un método de tratamiento de perturbaciones neuróticas, fundado en esa indagación, y 3) de una serie de intelecciones psicológicas, ganadas por ese camino, que poco a poco se han ido coligando en una nueva disciplina científica. (p. 231)

Toda vez que el psicoanálisis es también un método de investigación, la posibilidad de acercarse por medio de él a la lectura y reflexión de algunos fenómenos referidos a lo social es posible, aunque ellos no sean conceptos propios de la disciplina, pero están en relación con el sujeto y sus modos de goce, ejes centrales del método psicoanalítico. El presente artículo hace un recorrido 
por las formulaciones del psicoanálisis lacaniano para pensar la forma como el sujeto interactúa con lo social y como hace lazo con los otros en la contemporaneidad, cosa que, a su vez, necesariamente está referida al lazo social que impone el sistema capitalista neoliberal. Se trata de un artículo de revisión que dialoga desde el psicoanálisis con las condiciones del capitalismo neoliberal en relación con el lazo social y la formas como desde allí emerge el sujeto con sus goces.

\section{El capitalismo como discurso}

El psicoanálisis, a partir de la enseñanza de Jacques Lacan, se interesa en pensar el lazo social por cuanto este está indefectiblemente ligado al concepto de discurso, lo que supone que tal lazo social está basado en el lenguaje (Lacan, 2008c; Soler, 2011; Evans, 2007; Albano, et al. 2005) y que, por tanto, ese lenguaje involucra no solo al sujeto, sino también a aquel con el que se actúa, es decir, el otro al que el sujeto se dirige, pero, a su vez, "el efecto sobre el sujeto por la palabra que le es dirigida desde otra parte, por otro sujeto que ha sido olvidado, por otra localidad psíquica" (Evans, 2007, p. 73). En ese sentido, puede pensarse en la relevancia que adquiere la realidad para el método psicoanalítico, toda vez que para él esta se funda en el orden discursivo y por ello el lazo social regula al sujeto en la cultura, al tiempo que condiciona su subjetividad. Lo importante a destacar es que para Lacan (2008c) no hay realidad que pueda producirse fuera del discurso, ya que este define variaciones relacionales que configuran lo social. Esto indica que el discurso no cuenta con registros biológicos ni naturales, sino que va conforme a los modos como se organizan y constituyen los sujetos: el discurso conlleva efectos identificatorios y de división subjetiva; paradójicamente, y conforme al lazo social, puede reconocerse el que haya sujetos divididos, al tiempo que sujetados a las condiciones que regulan "(...) sus cuerpos, sus palabras, y sus conductas (...)” (Soler, 2011, p. 430), al ser vinculados con la estructura del lenguaje.

Así, desde lo propuesto por Lacan (2008c), es condición fundante que haya lenguaje para que exista y opere, posteriormente, un discurso. No se trata solo de palabras ordenadas de manera sistemática, sino que ellas mismas ordenan el lazo social que establecen los sujetos. Afirma el psicoanalista: "Mediante el instrumento del lenguaje se instaura cierto número de relaciones estables, en las que puede ciertamente inscribirse algo mucho más amplio, algo que va mucho más lejos que las enunciaciones efectivas" (Lacan, 2008c, p. 10). Pese a ello, el sujeto no puede utilizar ese "instrumento del lenguaje" (p. 10) a la medida de sus caprichos. Si bien es el lenguaje el que organiza esas "relaciones estables" (Lacan, 1970/2008, p. 10), es también el que, como instrumento, emplea al sujeto. Razón por la que se llega a afirmar que "(...) el lenguaje nos emplea, y por ese motivo eso goza" (Lacan, 1970/2008, p. 70). 
Los discursos, propuestos por Lacan en el Seminario 17 (2008c), funcionan con una estructura ordenada de maneras diferentes, según las posiciones que en ellos ocupen los cuatro elementos que los conforman, a saber, el agente, el trabajo, la verdad y la producción; además, se pretende con los discursos trascender la comunicación, operar más allá de las palabras. Esto quiere decir que la teoría psicoanalítica supone a los discursos sin un significado propio inherente, es decir, vacíos de significado pero impregnados de "la articulación significante" (p. 180), un "(...) dispositivo, cuya sola presencia, el hecho de que exista, domina y gobierna todas las palabras que eventualmente puedan surgir" (p. 180). Así, es el discurso el que opera como generador de enunciados y, por tanto, rige el lazo social que los sujetos establecen (Lacan, 2006) no solo entre ellos, sino de acuerdo a los elementos que componen cada discurso y también al lugar que ellos ocupan dentro del mismo.

La propuesta que lanza Lacan (2006) suscribe cuatro discursos y, por tanto, cuatro formas de lazo social efectos de tales discursos y del enlazamiento de sus componentes. Se formulan, entonces, desde el psicoanálisis (Lacan, 2008b), los discursos del Amo, de la Universidad, el Histérico y el del Analista. Estas cuatro formas discursivas posibles, a su vez están ordenadas por cuatro "letritas" (Lacan, 2008c, p. 182) que van cambiando de lugar y de función de acuerdo al discurso que opere y que, debido a que él excede a la palabra, "puede subsistir muy bien sin palabras" (p. 10); se trata de un "aparato" (p. 18) que tiene como condición característica una "estructura" (p. 10) "de cuatro patas, con cuatro posiciones" (p. 18). Estos cuatro elementos a los que el psicoanálisis nombra: agente, otro, producción y verdad (Lacan, 2008c), se presentan así organizados:

Figura 1. Estructura de los discursos propuesta por Jacques Lacan

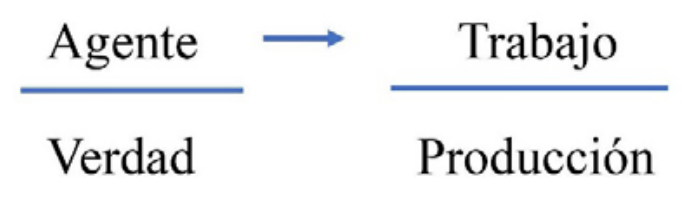

De acuerdo con la figura que propone Lacan aparece, en primer lugar, un agente, que se dirige a otro, y estos, tanto otro como agente, al estar encima de las barras funcionan como barrera de los dos elementos que están abajo y que permanecen ocultos, vedados para el sujeto, en este caso, la verdad y la producción. El agente, lugar inicial del discurso, nombrado también como "puesto de mando" (Lacan, 2008c, p. 112), si bien opera como un lugar donde se apoya el discurso, también funciona, dirá Lacan (2009, p. 25), a modo de "semblante", es decir, refiere a algo ilusorio, cuestión escópica que atrapa al sujeto. Ese agente dirigido a otro, a un trabajo, que se ubica en un lugar, “(...) hace parte del engranaje discursivo. Está situado dentro de esta maquinaria” (Sa- 
vio, 2015, p. 49). No se trata de algo externo al discurso, al dispositivo, sino que ese trabajo está dentro del discurso: "Son discursos sin la palabra, que luego se alojará en ellos" (Lacan, 2008c, p. 180). Es decir, ellos exceden las palabras, por tanto, opera un más allá de lo que un sujeto dice.

Por otro lado, debajo de la barra y al lado izquierdo, Lacan (2008c) ubica la verdad que, aunque reconoce como propulsor del discurso, también la enlaza con aquello imposible de decir totalmente, y que al estar del lado de lo latente (Alemán y Larriera, 1996), algo de ella escapa al decir, pues, como señala Lacan, está constituida como una estructura de ficción: "Eso dice algo sin saber lo que dice" (Lacan, 2008b, p. 184).

En último lugar, pero no menos importante, Lacan (2008c) ubica el elemento producción, que aparece del lado derecho por debajo de la barra y debajo del lugar del trabajo. Este lugar hace referencia al efecto del discurso, lo que este intenta producir pero nunca es alcanzado en su totalidad (Jurnaville, 1992), por lo que dirá Lacan que todo discurso apunta a ser "(...) rico en consecuencias", pero tales consecuencias resultan a su vez "oscuras" (Lacan, 2008c, p. 31).

En el lugar de cada elemento, Lacan (2008c) ubica también los términos correspondientes a los discursos para que ellos puedan operar. Estos son el S1 o significante amo, el S2 o cadena significante -que puede, dependiendo de qué discurso se trate, operar o no como saber-, el sujeto y el objeto $a$. Estos términos los va a ir rotando Lacan en el sentido de las manecillas del reloj para proponer los cuatro discursos inicialmente posibles, a saber, el de la universidad, el del amo, de la histérica y el del analista. Cada propuesta discursiva responde a una manera de estructuración del lazo social en el que cada uno de los términos ubicados en cada uno de los cuatro lugares posibles se entiende de una manera singular.

Así, el S1 o significante amo habilita y pone a operar el conglomerado de significantes, aunque él esté vaciado de significación y por sí mismo "no significa nada” (Lacan, 1981, p. 261), pues solo cobra significado si está ligado a los otros significantes. Son los S2 o el saber los que ligan precisamente esos significantes a modo de cadena, de red que amarra uno con otro (Rabinovich, 2007) y que tiene su efecto en el sujeto, aquel que el psicoanálisis propone necesariamente como dividido (Lacan, 2005), comandado por el inconsciente, y del que queda a su vez un resto, objeto $a$, causa de deseo que emerge de la intersección entre un sujeto y el Otro.

El primer discurso que formula Lacan, el del amo, refiere a una forma de lazo social antigua, planteada desde la dialéctica hegeliana, que contempla la dominación del amo desde la época de la esclavitud y la monarquía (Hegel, 1994; Lefevre, 1976). De las contribuciones hegelianas con respecto al lazo social, es posible atisbar el modo en que se define el encuentro del sujeto con el otro, basado en las mediaciones que posibilita el reconocimiento. El lazo social antiguo consiste en un esclavo que no tiene otra elección sino aceptar la vida que determina el amo. El psicoanálisis lacaniano interpreta el pensamiento hegeliano en función del nódulo conflictual que reúne la 
apuesta sobre la vida o la libertad entre el amo y el esclavo (Lacan, 2008c) y sostiene que hay, con base en el discurso amo, una lucha constante entre estos personajes: lucha a muerte, aspiración a obtener prestigio como forma de reconocimiento (Siep, 2015; Kojéve, 2012; Astrada y Korn 2005), lo que supone que el encuentro subjetivo fundamental del sujeto no sea sin el Otro, pues es este último que lo inscribe en una historia singular.

De acuerdo con lo anterior, para el psicoanálisis lacaniano el inconsciente, como discurso amo, está en relación al reconocimiento estructural de un deseo que contiene al sujeto y por el que define su lugar en los modos de construcción de un lazo con los otros. En tiempos actuales, donde emerge como amo el capitalismo y las formas como este se administra, se trata, particularmente, de entender los modos de dirección del goce y los mandatos que este impone y que el sujeto no puede domeñar a voluntad (Badiou y Roudinesco, 2019; Miller, 2019; Álvarez, 2006; Žižek, 1994), ni escapar de ellos toda vez que se ubican más allá del principio de placer y están en línea directa con los mandatos del superyó (Žižek, 1992). El psicoanálisis, con Lacan (2008c), reconoce que todo discurso posible, incluso el del analista, está en relación al goce.

En el discurso amo, propone Lacan (2008c), la figura del amo se ubica en el S1, que aparece en el lugar del agente. El amo lo que persigue es el funcionamiento del lazo social, ya que él pueda mantenerse como amo y gobernar, mientras que el esclavo, ubicado en el lugar del trabajo, posee el saber hacer, correspondiente a la cadena significante, S2 que se enlazan entre sí. El amo, en lugar de agente (S1), se dirige entonces al esclavo (S2), y de la relación entre ellos hay consecuentemente un producto y un efecto de verdad.

El discurso amo supone que, a partir del trabajo del esclavo y de la lectura que este hace del deseo del amo, se produce una verdad en relación a este último, a saber, que él también está en referencia a la castración. Enseña el psicoanálisis lacaniano: "como a través de ese trabajo el esclavo llega al saber absoluto, el amo no fue sino un instrumento, 'el magnífico cornudo de la historia"” (Lacan, 2008c, p. 184). Es decir, no estar eximido de la castración implica que aquel que agencia como amo está necesariamente sujeto a la falta y, por tanto, a la insatisfacción. En este discurso, el goce del lado del esclavo está ligado justamente a ese saber hacer y allí encuentra su anclaje el mandato del amo, que ocurre a su vez por la existencia del lenguaje. Es eso, señala Lacan (1972), lo que hace que el discurso funcione.

Ahora, pese a que ya había establecido cuatro discursos, Lacan (2008c) propone una quinta modalidad posible, "uno más respecto de esos cuatro" (Soler, 2011, p. 430). Se trata de una variación del discurso amo, que nombra como discurso capitalista, toda vez que el capitalismo empieza a emerger como "el amo moderno" (Lacan, 2008c, p. 32) y que se empieza a perfilar como sistema político y social que rige la cultura. Esto último atañe al psicoanálisis, entendiendo que todo discurso posible, incluido el capitalista, refiere al goce y que lo político no escapa a ese goce. Afirma Lacan (2008c): "solo es posible entrometerse en lo político si se reconoce que no hay 
discurso, y no solo analítico, que no sea del goce, al menos cuando de él se espera el trabajo de la verdad" (p. 83). Teniendo en cuenta que los discursos organizan un saber sobre la constitución del sujeto y su lugar en el lazo social, resulta relevante destacar el modo en que el capitalismo los afecta, de manera que "no logra escribir ningún vínculo entre los partenaires humanos" (Soler, 2001, p. 144). El discurso capitalista borra la singularidad del sujeto al incorporarlo dentro de sus procesos de producción y consumo. En este sentido, el saber capitalista se dirige no solo al equipamiento y sostenimiento económico del conglomerado social, sino también a despojar al sujeto de su diferencia subjetiva conforme al consumismo desenfrenado.

El sujeto del capitalismo, dividido subjetivamente como función de discurso, se vincula con un tipo de saber encaminado a producir objetos afines al goce del consumismo. El auge capitalista, a través de la transformación del discurso amo, se basa en el imperativo que relanza una y otra vez al sujeto a gozar con frenesí: el capitalismo conforma "un circuito cerrado, continuo, sin ruptura, donde se puede decir también que es tanto el sujeto como el producto los que ordenan" (Soler, 2001, p. 144).

En el discurso capitalista (Lacan 2008c) opera una variación que implica que el sujeto que se ubicaba en el discurso amo desde el lugar de la verdad, pasa a ser el agente y, en consecuencia, el $\mathrm{S} 1$ pasa al lugar de la verdad, quedando del lado izquierdo bajo la barra del agente. Esta variación implica que la secuencia sujeto, S1, S2, objeto $a$, no se sigue más y, consecuentemente, el S2 ya no está regulado por el S1 (Lamovsky, 2012), condición que conlleva el desdibujamiento de los límites y el avance desbocado de la ciencia. Si el límite que suponía el discurso amo se borra, los objetos de consumo, fuentes de goce, hacen su emergencia excesivamente, dejando al sujeto a su vez consumido por ellos (Lacan, 1972).

Así, se trata de un hacer que está desarticulado de la verdad, en la que el sujeto queda despojado de saber y se rompe entonces la articulación posible entre verdad y goce. Por ello, "lo que se produce en el paso del discurso del amo antiguo hasta el del amo moderno, que llamamos capitalista, es una modificación en el lugar del saber” (Lacan, 2008c, p. 32). Al sujeto: “(...) la explotación capitalista le frustra de su saber, volviéndolo inútil. Pero el que se le da a cambio en una especie de subversión, es otra cosa, un saber de amo. Por eso no ha hecho más que cambiar de amo" (p. 32).

Si en el discurso capitalista el sujeto ha cambiado de amo, este último induce ahora a la satisfacción, pues los límites se han vuelto inexistentes. La frontera de la Ley, ahora borrada, hace emerger incesantemente y de manera particular para el uno y cada uno el plus de gozar (Lacan, 2008c), entendido este como aquel resto efecto de la propia satisfacción al que el sujeto debe renunciar, quedando perdido, a expensas de su goce que aparentemente es completado con objetos que el mercado ofrece cada día más novedosos y que son ofertados so pretexto no solo de ser alcanzables, sino también de contribuir al avance de la ciencia. Ese plus de gozar fue equiparado 
por Lacan (2008c) con la propuesta de la plusvalía que lanzara Karl Marx (2014) como aquello a lo que el trabajador debe renunciar y que implica, a su vez, la reinversión del capitalista en el proceso de producción.

Lo anterior encuentra su dificultad frente al deseo, toda vez que el discurso capitalista parece ordenarse por la voluntad de goce, quedando el sujeto en el lugar del agente, allí donde antes se encontraba el significante amo, ahora el sujeto "desconoce la relación entre el discurso y el significante que lo constituye" (Aranda-Sánchez, 2018, p. 12) y el objeto que causaba el deseo ha sido sustituido así por el objeto de goce, poniendo de plano la posibilidad de prescindir del Otro y dejando al sujeto a la misma suerte de los objetos, esto es, consumido.

El discurso capitalista implica, entonces, una particular forma de establecimiento social que parece imperar en la contemporaneidad. En él, posteriormente encuentra su soporte el neoliberalismo como sistema político, haciendo posible hablar de un capitalismo neoliberal y allí, en la cultura en que este opera, se encuentra inmerso el sujeto que termina respondiendo frente a ese capitalismo neoliberal, que se instituye como discurso de la época actual con demandas que le son propias (Soler, 2011). Es menester, pues, si se pretende pensar las lógicas subjetivas que aparecen en la actualidad y que afectan el lazo social, pensar en la incidencia subjetiva del neoliberalismo por cuanto este, a su vez, es efecto y tiene su soporte en el discurso capitalista.

\section{El sistema capitalista neoliberal}

Posterior a la Segunda Guerra Mundial (1939-1945), y preocupados por la devastación que ella había dejado, así como por la posibilidad de alcanzar una convivencia en paz entre naciones, era menester "construir cierta forma de compromiso de clase entre el capital y la fuerza de trabajo" (Harvey, 2007, p. 16); esto, teniendo en cuenta que los dos sistemas político-sociales vigentes, a saber, tanto el socialismo como el capitalismo habían evidenciado fracasos (Dahl y Lindblom, 1971). Empero, las preocupaciones de las naciones alrededor de la devastación que había dejado la guerra empezaron poco antes de finalizar la Segunda Guerra Mundial y, en 1944, durante el mes de julio, se llevó a cabo la Conferencia monetaria y financiera de las Naciones Unidas, en la que nacen los Acuerdos de Bretton Woods, que empiezan a regular el orden económico internacional referido a las relaciones comerciales y financieras entre potencias (Aranda, 15 de noviembre de 2008) e instituyen el dólar estadounidense como moneda internacional y también abren el paso a la creación del Fondo Monetario Internacional (FMI) y el Banco Mundial (BM), instituciones que tenían como objeto "contribuir a la estabilización de las relaciones internacionales" (Harvey, 2007, p. 16). 
Lo anterior, además de promover las relaciones comerciales armónicas entre naciones, siempre que ellas estuvieran regidas por lo establecido en los Acuerdos de Bretton Woods (Mizrahi, 30 de junio de 2019) y mediadas por el dólar estadounidense como moneda de cambio, también dio paso a que en Europa emergieran algunos Estados que operaban desde las políticas de la social democracia (Harvey, 2007), promoviendo la justicia social en el marco del sistema capitalista y que, contrarios a la apuesta de los Estados Unidos, sin embargo pretendían también el crecimiento económico del Estado que gobernaban, afianzado este en el aumento y aseguramiento de empleos y el bienestar ciudadano, de manera alterna a que el poder estatal vigilara e interviniera en los procesos de mercados. Tal cosa garantizaba, a su vez, el objetivo inicial del compromiso entre el capital y la fuerza de trabajo y, con ello, se pretendía alcanzar una convivencia en paz. Este nuevo sistema se conoció como "liberalismo embridado" (Harvey, 2007, p. 17); en él, si bien eran posibles las relaciones comerciales entre países, de acuerdo a lo pactado, ello también se regía por normas mundiales que con regulaciones burocráticas permitían que dichas relaciones comerciales no ocurrieran de cualquier manera ni desbocadamente (Brenner et al., 2011; Piñero, 2012; Camargo-Lombana, 2016).

Pese a esas políticas regulatorias, en la década de los años sesenta el sistema de "liberalismo embridado" (Harvey, 2007, p. 17) empezó a declinar, haciendo visibles sus efectos, provocados por la equiparación del dólar al oro y evidenciando dificultades en torno a la operatividad del sistema capitalista, que si bien posibilitaba la acumulación de capital, también empezó a dejar ver algunas dificultades referentes a la falta de control de Estados Unidos sobre su propia moneda (Caruncho, 2018; Chamorro, 2017; Martínez-Matías, 2016) que, en ese entonces, de cara a la apertura promulgada en Bretton Woods, se consignaba en los bancos europeos y se propagaba por el mundo entero. Todo esto llevó a que, al iniciar la década de los setenta, se abandonara el sistema de cambio fijo, más cuando el oro no podía seguir respaldando al dólar como cambio internacional, lo que a su vez posibilitó los cambios fluctuantes de la moneda en 1971 y los potencializó a partir de 1973 con la crisis del petróleo cuando la Organización de Países Exportadores de Petróleo (OPEP) ordenó el embargo de los envíos petrolíferos a Estados Unidos.

Las situaciones antes descritas pusieron de plano el fracaso del sistema, dada la imposibilidad para controlar la inflación y, con ella, la maximización del déficit fiscal de Estados Unidos. Si bien el "liberalismo embridado" (Harvey, 2007, p. 17) había permitido inicialmente la acumulación de capital, presentaba ahora inconvenientes, ya que este no circulaba y tampoco se tenía suficiente control sobre él, lo que traía efectos económicos adversos a los esperados inicialmente, referidos al crecimiento económico y el mantenimiento de EE. UU. como potencia mundial de la cual dependían otras naciones.

Lo anterior, de la mano de la presencia de la crisis económica y social que se vivía en América Latina, así como del giro hacia políticas neoliberales dado por el BM y el FMI, y la aplicación de las mismas en diversos países como Gran Bretaña en Europa y Chile en América Latina, liderados 
por su gobierno de turno, llevó a que posteriormente, en 1989 de la mano de John Williamson, se acuñara el término "Consenso de Washington" (Harvey, 2008, p. 8), intentando enfrentar los excesivos beneficios económicos que recibían algunos países posterior a la crisis de los años setenta, así como también una forma de salida posible a la deuda externa que enfrentaban los países menos beneficiados económicamente y frente la cual el FMI, el BM y la Reserva Federal de Estados Unidos (EE.UU.) parecían coincidir en los nuevos direccionamientos económicos que garantizaban el sostenimiento y manejo financiero de las naciones (Castañeda y Díaz-Bautista, 2017).

El Consenso de Washington se formuló, entonces, como un decálogo de medidas que tenía como fundamento políticas económicas que pretendían la disminución del gasto público que, a su vez, se vería reflejado en la baja del déficit de cada nación. Para ello, se propendía también por la privatización de empresas públicas que eran vendidas y tercerizadas, de manera que al Estado con tales ventas les aumentara su capital financiero, así también se desregularizaba el mercado laboral interno y se aumentaban las condiciones para inversiones extranjeras (Bidaurratzaga y Zabalo, 2012). Este conjunto de normativas marca un punto importante en las concepciones posteriores de las políticas neoliberales que se mantienen hasta la actualidad. Se trata de un pequeño giro neoliberal en el que se pasa de pensar el desarrollo económico centrado en la satisfacción de las necesidades básicas, la eliminación del desempleo y de la pobreza -que eran las banderas en los inicios de los años setenta-; con el Consenso de Washington, en la década siguiente, esas luchas económicas quedan de lado, dando paso a que la prioridad sea el apoyo a la empresa privada, pues esta es concebida en el capitalismo neoliberal como el centro que impulsa el desarrollo económico.

Lo anterior pone de plano el intento de homogenización de la economía, de globalización, pues lo pretendido, incluso poco antes del Consenso de Washington y que quedara formulado con las diez medidas que dicho Consenso proponía, era que todos los países, sin importar su contexto, debían acogerse a unos parámetros económicos globalizantes, que dejaban de lado la particularidad de cada nación, independientemente de su nivel de desarrollo, cosa que se agudizó con la crisis que se vivía en América Latina y con la caída del muro de Berlín en 1989 y permitió que el capitalismo neoliberal se expandiera por muchas naciones del mundo a partir de la década de los noventas.

Lo anterior contrastaba fuertemente con las anteriores políticas económicas propuestas por John Maynard Keynes, que suponían lo opuesto a lo pretendido en los años setenta a partir de la crisis del petróleo. Keynes propendía desde la década de los años 30 por el intervencionismo del Estado en el sector financiero, pues concebía que el capitalismo como sistema político y económico, sin la intervención y regulación del Estado, presentaba dificultades para la generación de empleo y también complicaciones relativas al gasto público, por lo que tal cosa era necesaria no solo para permanecer en el sistema económico capitalista, sino también para estabilizar la economía (Keynes, 1998) y propiciar el empleo. 
Así, de frente al panorama de la apertura de mercados propuesto por el Consenso de Washington y con el ascenso de Margaret Thatcher en 1979 al Primer Ministerio de Reino Unido y, de Ronald Reagan en 1981 a la Presidencia de Estados Unidos hasta 1989, el neoliberalismo cobró más fuerza, toda vez que ambos líderes no solo eran referentes en sus respectivos países, sino también en el mundo, pues las naciones que dirigían se habían consolidado como potencias económicas. Tanto Thatcher desde Inglaterra, como Reagan en los Estados Unidos promovieron la liberalización de la economía, la apertura de los mercados y las políticas contrarias a las ideas keynesianas o de intervencionismo del Estado (Bidaurratzaga y Zabalo, 2012).

Lo anterior, sumado a la acumulación de la deuda externa de las naciones, la crisis económica de México de 1982 y a la influencia del BM y del FMI en Sur América, Asia y África, pretendía ofrecerse como salida a aquellos países que se encontraban frente a dificultades financieras, ofertando por medio del BM y del FMI plazos de financiación para aquellos países con problemas para el pago de su deuda externa. Acceder a esta financiación implicaba, a su vez, cambios estructurales con respecto al modelo económico, que a partir de entonces eran direccionados por esas entidades internacionales. Las naciones suramericanas, africanas y asiáticas que se acogieron a esta propuesta tuvieron que redireccionar su economía, ahora comandada desde el modelo neoliberal y entidades financieras externas apoyadas por Estados Unidos y, finalmente, terminaron incluso impactando a Europa, cosa que quedara expresada en la frase de Richard Nixon (19131994): "ahora todos somos liberales de mercado, neoliberales" (Nixon, citado por Sader, 2014).

Así, la economía mundial giró sus políticas hacia el modelo neoliberal que exigía la renuncia a cualquier tinte keynesiano posible y encontraba su soporte en el FMI y el BM, ofertados como entidades salvadoras que, a su vez, se fundamentaban en políticas capitalistas neoliberales que propendían no solo por la privatización de empresas estatales, sino por el mínimo intervencionismo del Estado para control y regulación del sector privado y también por la libre oferta y demanda, lo que trae consigo la acumulación excesiva de capital en pocas manos privadas.

Lo anterior da cuenta que el capitalismo neoliberal emerge como un sistema político y social que intenta desde su nacimiento frenar el fracaso que evidenció previamente el capitalismo, incluso el dirigido con las ideas keynesianas, reorganizándolo y abonando "las condiciones para la acumulación del capital y restaurar el poder de las elites económicas” (Harvey, 2007, p. 25). Si bien el capitalismo neoliberal se puso a operar como un sistema que buscaba el restablecimiento de la economía capitalista, en los tiempos actuales este es denunciado de manera insistente (Collins et al., 2015) e incluso frente a organismos internacionales, porque su fundamentación del libre mercado y ausencia del control del Estado ha traído consigo también las mayores tasas de desigualdad en la historia de los pueblos que a él se han adherido. 
Así, el sistema capitalista neoliberal, regente en la contemporaneidad, ha empezado a ser foco de preocupación de las diversas ciencias sociales y humanas, pues si bien pareciera haber funcionado muy bien para los grandes capitales que pueden exportar sus productos y para aquellos que ostentan el poder financiero, permitiendo que ellos se acrecienten más, no es menos cierto que, a su vez, según los indicadores del BM (2021), las tasas de pobreza y miseria también se han acrecentado, dando cuenta de que 700 millones de habitantes en el mundo viven en la pobreza extrema, como también siguen siendo de difícil acceso para buena parte de la población los productos básicos ligados no solo a las cuestiones alimentarias, sino a servicios fundamentales como la energía y el agua (BM, 2021). Bajo estas condiciones, es menester preguntarse por el lugar del sujeto cuando este se encuentra dentro de gobiernos regidos por el sistema capitalista neoliberal, toda vez que él no solo es el centro sobre el que opera dicho sistema (Touraine, 2014), sino que se vuelve necesariamente objeto de producción de este, con su fuerza de trabajo y también con aquello que le es más propio, a saber, el goce.

\section{Conclusiones}

El discurso capitalista neoliberal, al promover el consumismo de objetos como prioridad del mercado, establece vínculos específicos con el goce. El auge del capitalismo neoliberal implica el exceso de goce e impone al sujeto el cumplimiento de cierta satisfacción y trae consigo la producción de una nueva lógica subjetiva que destina, a diferencia del amo antiguo, al esclavo no solo a desear inconscientemente, sino a verse identificado con el amo contemporáneo en tener que asumir como propios los mandatos de este. El sistema en cuestión afecta al sujeto, le excede, toda vez que "(...) el capitalismo no es un sistema ubicado en un solo Estado, está incrustado en un sistema - mundo, por definición, más grande que cualquier Estado" (Wallerstein, 2015, p. 21). El sujeto que produce el sistema capitalista neoliberal está compelido a gozar sin tregua por imperativos consumistas que prometen una supuesta felicidad.

Por otra parte, se imponen en el esclavo prácticas solidarias con la acumulación de capital. El capitalismo neoliberal sostiene mecanismos de explotación que operan tácitamente en el campo laboral: la tendencia a una imaginaria democratización en el trabajo (Sequera-Fernández, 2017) compromete las decisiones del sujeto basadas entonces en una supuesta equidad entre él y el capitalista-empresario. De este modo, a diferencia del capitalismo burocrático y vertical de posguerra, se crea un sistema aparentemente horizontal que incorpora las capacidades empoderadas del trabajador como aquellas acordes a las políticas de rendimiento de las empresas. 
Los trabajadores se entregan a un mundo competitivo para no verse excluidos del modelo de mercado actual que suponen actúa como resguardo de sus derechos como sujetos partícipes de la globalización. Esto indica que el capitalismo neoliberal pregona y promueve el modelo de mercado como función económica y política que debe ser defendida y sostenida, asegurándose que tal cosa sea hecha por los mismos trabajadores a quienes, paradójicamente, se usufructúa en sus capacidades. Así:

El sujeto del rendimiento, que se pretende libre, es en realidad un esclavo. Es un esclavo absoluto, en la medida en que sin amo alguno se explota a sí mismo de forma voluntaria. No tiene frente a sí un amo que lo obligue a trabajar. El sujeto del rendimiento absolutiza la mera vida y trabaja. La mera vida y el trabajo son dos caras de la misma moneda. (Han, 2017b, p. 12)

Este sistema apela a la protección de sus políticas mercantiles y consumistas mediante un conformismo social respaldado en la condición de sujetos dóciles e incapaces de sublevarse. Cada miembro de la sociedad, obturado en su división constitutiva, se cree capaz de superar su desdicha cuando consume los objetos producidos por el mercado, que intenta satisfacer toda demanda de felicidad posible como aspiración de los hombres en la vida (Freud, 1992d).

Bajo el intento de alcanzar ese ideal de felicidad, el neoliberalismo tiene su influencia sobre la subjetividad y el lazo social, dejando al sujeto consumido por los objetos que consume -acorde a la afirmación de Dufour (2007)-, haciendo emerger como ilusión de progreso cuerpos que operan en torno a la producción del mercado y, además: "Como si el pleno desarrollo de la razón instrumental (la técnica) permitido por el capitalismo, se saldara a costa de un déficit de la razón pura" (Dufour, 2007, p. 16).

Es decir, la operativización de mercado en la que se basa el capitalismo con su consecuente sistema neoliberal deja en evidencia una dificultad en la que los sujetos solo pueden aparecer en cuanto poseen bienes ofertados por el mercado, en donde "consumir significa invertir en la propia pertenencia a la sociedad" (Bauman, 2008, p. 82). Tal cosa incide en la desregularización del lazo social que ahora, desde el influjo del neoliberalismo, aparece fisurado, dejando a los sujetos como gestores de su propio bienestar, sin tener en cuenta, las más de las veces, la presencia del otro, haciendo evidente la imposibilidad de la asunción afectiva del prójimo, poniendo de plano que si esto es posible no solo el lazo social ha sido afectado, sino que también el goce aparece de forma desmesurada, posibilitando la emergencia de sujetos solitarios, imposibilitados para comprometerse más allá de su propio narcisismo con causas colectivas que favorezcan los lazos solidarios.

Si bien el sistema neoliberal ofrece aparentemente el alcance desmesurado de objetos de consumo ofertados en diferentes seriales de marca que evidencian su abundancia (Baudrillard, 2004), y en los que "para incrementar la productividad, no se superan resistencias corporales, sino que se optimizan procesos psíquicos y mentales" (Han, 2017b, p. 42), a su vez pone de plano que, pese a que en ocasiones los objetos se puedan adquirir, tal cosa no resuelve la pregunta por el alcance 
de la dicha que persigue el humano. Para reiterar, es posible entrar gozosamente en el sistema de oferta y demanda desbordada propuesto por el neoliberalismo; pese a ello, esta operación ratifica lo que el psicoanálisis reconoce como constitutivo de la subjetividad, a saber, la falta (Lacan, 2008a; Stavrakakis, 2010). No porque se pueda consumir más, tener más, el sujeto queda desprovisto de su falta. En efecto, ella aparece insistentemente, exponiendo al sujeto a la miseria que, pese a la abundancia de objetos, resulta evidente (Dipaola y Lutereau, 2015) y que reproduce el vacío, la nada con la que el humano tiene que lidiar.

Aparecen sujetos sin conmiseración por el otro, por el semejante. Si bien, lo que postula la obra freudiana es que dentro de la cultura cada hombre tiene derecho a establecer y llevar su vida en la forma que pueda (Freud 1992e), tal cosa, no desconoce que “(...) la creencia en la «bondad» de la naturaleza humana es una de esas miserables ilusiones que, según los hombres esperan, embellecerán y aliviarán su vida, cuando en realidad sólo les hacen daño" (Freud, 1992f, p. 96). Ahora bien, es la posibilidad de creer ilusoriamente en la bondad del otro, lo que el capitalismo neoliberal bajo el estandarte de que todo humano es mercancía desconoce, dejando entonces al sujeto a merced no solo de los objetos de consumo, sino a su vez identificado también al lugar de ser un objeto más, consumible y consumado por el capitalismo y en su forma más extrema por el sistema neoliberal.

\section{Conflicto de intereses}

Los autores declaran la inexistencia de conflicto de interés con institución o asociación comercial de cualquier índole.

\section{Referencias}

Albano, S., Levit, A., \& Naughton, V. (2005). Lacan: Redes, nudos, mapas y fórmulas: Vol. 1. Significante y sujeto. Quadrata.

Alemán, J., \& Larriera, S. (1996). Desde Lacan: Heidegger. Ediciones del Cifrado.

Alemán, J. (2012). Soledad común. Políticas en Lacan. Capital Intelectual. 
Alemán, J. (14 de marzo de 2013). Neoliberalismo y subjetividad. Página 12. https://www.pagina12.com.ar/diario/contratapa/13-215793-2013-03-14.html

Álvarez, A. (2006). La teoría de los discursos en Jacques Lacan. Letra Viva.

Aranda, J. (15 de noviembre de 2008). ¿Qué fue Bretton Woods?” El País. https://elpais.com/ economia/2008/11/15/actualidad/1226737974_850215.html

Aranda-Sánchez, J. (2018). Discurso capitalista y el imperio de las imágenes en el horizonte contemporáneo. El Ornitorrinco Tachado, (7), 9-20. https:/ornitorrincotachado.uaemex.mx/ article/view/4728/8424

Astrada, C., \& Korn, A. (2005). Hegel y Marx. Quadrata.

Badiou, A., \& Roudinesco, E. (2019). Jacques Lacan, pasado, presente. Diálogos. Nmesis.

Banco Mundial. (BM). 2021. Informe sobre el desarrollo mundial 2021: datos para una vida mejor. International Bank for Reconstruction and Development/The World Bank. https:// www.worldbank.org/en/publication/wdr2021

Baudrillard, J. (2004). El sistema de los objetos. Siglo XXI. (Obra original publicada en 1970).

Bauman, Z. (2008). Vida de consumo. Fondo de Cultura Económica.

Bidaurratzaga, E., \& Zabalo, P. (2012). Los Acuerdos de Asociación de la UE con África y América Latina: La nueva apuesta europea por Tratados de Libre Comercio con cooperación. Estudios de Economía Aplicada, 30(3), 837-860. http://ojs.ual.es/ojs/index.php/eea/article/view/3607

Brenner, N., Peck, J., \& Theodore, N. (2011). ¿Y después de la neoliberalización? Estrategias metodológicas para la investigación de las transformaciones regulatorias contemporáneas. Urban, (1), 21-40. http://polired.upm.es/index.php/urban/article/view/409/1878

Butler, J., Laclau, E., \& Žižek, S. (2017). Contingencia, hegemonía, universalidad: diálogos contemporáneos en la izquierda. Fondo de Cultura Económica.

Camargo-Lombana, E. (2016). Derecho a la salud bajo el modelo neoliberal colombiano. Derecho y Realidad, 14(28), 23-40. https://doi.org/10.19053/16923936.v14.n28.2016.7810 
Caruncho, L. (2018). Las cosas por su nombre. Un estudio de la racionalidad subjetiva del neoliberalismo a partir del análisis de los Principios Institucionales del PRO (2018). Entramados y Perspectivas, 8(8), 360-391. https://publicaciones.sociales.uba.ar/index.php/entramadosyperspectivas/article/view/2969/2615

Castañeda, V., \& Díaz-Bautista, O. (2017). El Consenso de Washington: algunas implicaciones para América Latina. Apuntes del Cenes, 36(63), 15-41. http://dx.doi.org/10.19053/01203053. v36.n63.2017.4425

Castillo, J. C., Torres, A., Atria, J., \& Maldonado, L. (2019). Meritocracia y desigualdad económica: Percepciones, preferencias e implicancias. Revista Internacional de Sociología, 77(1), e117. https://doi.org/10.3989/ris.2019.77.1.17.114

Chamorro, E. (2017). ¡Que no me hablen más de Marx!: Foucault, el neoliberalismo y lo intolerable. En E. Chamorro (Ed.), Michel Foucault y los sistemas de pensamiento. Una mirada histórica (pp. 377-391). Cenaltes.

Collins, R. (2015). Ya no hay escape: el fin de las posibilidades de empleo para la clase media. En ¿Tiene futuro el capitalismo? (pp. 88-121). Siglo XXI Editores.

Dahl, R., \& Lindblom, C. (1971). Política, económica y bienestar: la planificación y los sistemas político-económicos reducidos a procesos. Harper \& Bros. (Obra original publicada en 1953).

Dipaola, E. M., \& Lutereau, L. (2015). El discurso capitalista y el goce de lo que se consuma: Lacan y la cultura contemporánea. Diferencias, 1(1), 19-39. http://www.revista.diferencias. com.ar/index.php/diferencias/article/view/8/3

Dufour, D. R. (2007). El arte de reducir cabezas. Paidós.

Evans, D. (2007). Diccionario introductorio de psicoanálisis lacaniano. Paidós.

Freud, S. (1992a). Pulsiones y destinos de pulsión. En Obras completas (vol. XIV, pp. 105-134). Amorrortu Editores S.A. (Obra original publicada en 1915).

Freud, S. (1992b). Más allá del principio de placer. En Obras completas (vol. XVIII, pp. 1-62). Amorrortu Editores S.A. (Obra original publicada en 1920).

Freud, S. (1992c). Dos artículos de enciclopedia: "Psicoanálisis" y "Teoría de la libido". En Obras completas (vol. XVIII, pp. 227-254). Amorrortu Editores S.A. (Obra original publicada en 1923). 
Freud, S. (1992d). El malestar en la cultura. En Obras completas (vol. XXI, pp. 57-140). Amorrortu Editores S.A. (Obra original publicada en 1930).

Freud, S. (1992e). ¿Por qué la guerra? En Obras completas (vol. XXII, pp. 179-198). Amorrortu Editores S.A. (Obra original publicada en 1932).

Freud, S. (1992f). Nuevas conferencias de introducción al psicoanálisis. 32a conferencia. Angustia y vida pulsional. En Obras completas (vol. XXII, pp. 75-103). Amorrortu Editores S.A. (Obra original publicada en 1933).

González-Rey, F. (1997). Epistemología cualitativa y subjetividad. EDUC.

Han, B. C. (2017a). La sociedad del cansancio. Editorial Herder.

Han, B. C. (2017b). Psicopolítica. Neoliberalismo y nuevas técnicas de poder. Editorial Herder.

Harvey, D. (2007). Breve historia del neoliberalismo. Akal.

Harvey, D. (2008). El neoliberalismo como destrucción creativa. Apuntes del Cenes, 27(45), 3-25. https://revistas.uptc.edu.co/index.php/cenes/article/view/3032/2747

Hegel, G. (1994). Fenomenología del espíritu. Fondo de Cultura Económica. (Obra original publicada en 1807).

Jurnaville, A. (1992). Lacan y la filosofía. Ediciones Nueva Visión.

Keynes, J. M. (1998). Teoría general del empleo, el interés y el dinero. Ediciones Aosta. (Obra original publicada en 1936).

Kojéve, A. (2012). La dialéctica del amo y del esclavo en Hegel. Leviatán.

Lacan, J. (1972). “Conferencia de Milán”. Disertación pública de Jacques Lacan en la Universidad de Milán convocada mediante la nominación "Del discurso psicoanalítico". En: En Italie Lacan (pp. 58-77) La salamandra. (Obra original publicada en 1978)

Lacan, J. (1981). El Seminario de Jacques Lacan, Libro 3: Las psicosis. Paidós. (Obra original publicada en 1955).

Lacan, J. (1984). El estadio del espejo como formador de la función del yo [Je] tal como se nos revela en la experiencia psicoanalítica. En Escritos 1 (pp. 86-93). Siglo XXI Editores. (Obra original publicada en 1949). 
Lacan, J. (2005). El Seminario de Jacques Lacan, Libro 23: El sinthome. Paidós. (Obra original publicada en 1975).

Lacan, J. (2006). Psicoanálisis, radiofonía y televisión. Editorial Anagrama. (Obra original publicada en 1977).

Lacan, J. (2008a). El Seminario de Jacques Lacan, Libro 4: La relación de objeto. Paidós. (Obra original publicada en 1956)

Lacan, J. (2008b). El Seminario de Jacques Lacan, Libro 16: De un Otro al otro. Editorial Paidós. (Obra original publicada en 1969).

Lacan, J. (2008c). El Seminario de Jacques Lacan, Libro 17: El reverso del psicoanálisis. Paidós. (Obra original publicada en 1970).

Lacan, J. (2009). El Seminario de Jacques Lacan, Libro 18: De un discurso que no fuera del semblante. Paidós. (Obra original publicada en 1971).

Laclau, E., \& Mouffe, Ch. (2015). Hegemonía y estrategia socialista. Hacia una radicalización de la democracia. Fondo de Cultura Económica.

Lamovsky, L. (2012). ¿El discurso capitalista es un discurso? Escuela Freudiana de Buenos Aires (EFBA). http://www.efbaires.com.ar/files/texts/TextoOnline_1432.pdf

Lefevre, H. (1976). Hegel, Marx, Nietzsche (o el reino de las sombras). Siglo XXI Editores.

Martínez-Matías, P. (2016). Del neoliberalismo como ideología. Logos. Anales del Seminario de Metafísica, 49, 161-187.https://doi.org/10.5209/rev_ASEM.2016.v49.53177

Marx, K. (2014). El Capital: crítica de la economía política. El proceso de producción del capital. Tomo I. Fondo de Cultura Económica. (Obra original publicada en 1867).

Miller, J. A. (2019). Del sintoma al fantasma y retorno. Los cursos psicoanalíticos de JacquesAlain Miller. Paidós.

Mizrahi, D. (30 de junio de 2019). A 75 años de Bretton Woods, el pacto que diseñó el orden económico global que hoy se está desmoronando. Infobae. https:/www.infobae.com/america/ mundo/2019/06/30/a-75-anos-de-bretton-woods-el-pacto-que-diseno-el-orden-economico-global-que-hoy-se-esta-desmoronando/ 
Piñero, M. T. (2012). Recuperando la autonomía en la política exterior. En Política y desborde. Más allá de una democracia liberal (pp. 183-202). Eduvin.

Polanyi, K. (2003). La gran transformación. Fondo de Cultura Económica.

Rabinovich, D. (2007). El deseo del psicoanalista. Libertad y determinación en psicoanálisis. Manantial.

Sader, E. (2014). La derecha en el neoliberalismo. América Latina en Movimiento, consultado el 15 de noviembre, 2019, https://www.alainet.org/es/articulo/82908

Savio, K. (2015). Aportes de Lacan a una teoría del discurso. Folios, (42), 43-54. http://www. scielo.org.co/pdf/folios/n42/n42a04.pdf

Sequera-Fernández, J. (2017). Ante una nueva civilidad urbana. Capitalismo cognitivo, habitus y gentrificación. Revista Internacional de Sociología, 75(1), e055. https://doi.org/10.3989/ ris.2017.75.1.15.31

Siep, L. (2015). El camino de la fenomenología del espíritu: un comentario introductorio al escrito sobre la diferencia y la fenomenología del espíritu de Hegel. Editorial Anthropos.

Soler, C. (2001). El padre síntoma. Asociación Foro del Campo Lacaniano de Medellín.

Soler, C. (2011). Incidencias politicas del psicoanálisis. 45 ensayos y conferencias (Vol. 1). S\&P.

Stavrakakis, Y. (2010). La izquierda lacaniana. Psicoanálisis, teoría y política. Fondo de Cultura Económica.

Touraine, A. (2014). Crítica de la modernidad. Fondo de Cultura Económica.

Wallerstein, I. (2015). La crisis estructural, o por qué los capitalistas ya no encuentran gratificante al capitalismo. En: ¿Tiene futuro el capitalismo? (pp. 15-46). Siglo XXI Editores.

Žižek, S. (1992). El sublime objeto de la ideología. Siglo XXI Editores.

Žižek, S. (1994). Goza tu síntoma. Jacques Lacan dentro y fuera de Hollywood. Nueva Visión.

Žižek, S. (2016). El resto indivisible. Ediciones Godot. 